\title{
What research tells us about knowledge transfer strategies to improve public health in low-income countries: a scoping review
}

\author{
Stéphanie Siron · Christian Dagenais · Valéry Ridde
}

Received: 10 March 2015/Revised: 3 July 2015/Accepted: 8 July 2015/Published online: 23 August 2015

(C) The Author(s) 2015. This article is published with open access at Springerlink.com

\begin{abstract}
Objectives This study describes the current state of research on knowledge transfer strategies to improve public health in low-income countries, to identify the knowledge gaps on this topic.

Methods In this scoping review, a descriptive and systematic process was used to analyse, for each article retained, descriptions of research context and methods, types of knowledge transfer activities and results reported. Results 28 articles were analysed. They dealt with the evaluation of transfer strategies that employed multiple activities, mostly targeting health professionals and women with very young children. Most often these studies used
\end{abstract}

This review is part of the special issue "Driving the Best Science to Meet Global Health Challenges" edited on the occasion of the 9th European Congress on Tropical Medicine and International Health 2015.

Electronic supplementary material The online version of this article (doi:10.1007/s00038-015-0716-5) contains supplementary material, which is available to authorized users.

S. Siron · C. Dagenais $(\square)$

Department of Psychology, University of Montreal,

Pavillon Marie-Victorin, Room C355, Centre-ville Station,

P.O. Box 6128, Montreal, QC H3C 3J7, Canada

e-mail: christian.dagenais@umontreal.ca

S. Siron

e-mail: stephanie.siron@umontreal.ca

V. Ridde

School of Public Health, University of Montreal, 7101, Avenue du Parc, 3rd Floor, Montreal, QC H3N 1X9, Canada

e-mail: valery.ridde@umontreal.ca

V. Ridde

University of Montreal Public Health Institute (IRSPUM),

Montreal, Canada quantitative designs and measurements of instrumental use with some methodological shortcomings. Results were positive and suggested recommendations for improving professional practices, knowledge and health-related behaviours. The review highlights the great diversity of transfer strategies used, strategies and many conditions for knowledge use.

Conclusions The review provides specific elements for understanding the transfer processes in low-income countries and highlights the need for systematic evaluation of the conditions for research results utilization.

Keywords Scoping review - Public health · Low-income countries - Knowledge transfer . Research utilization

\section{Introduction}

In its 2013 annual report, the World Health Organization (WHO) showed the extent to which scientific research can support low-income countries in achieving universal healthcare coverage (WHO 2013a). Regarding maternal and child health, the United Nations affirms that "we know what works" and "what we should do" (United Nations Secretary-General 2010). There have been countless international reports and studies explaining "what works" in fields as varied as nutrition, health services, or the fight against malaria (Allen and Gillespie 2001; Levine and What Works Working Group 2004; Peters et al. 2009). Even so, despite major advances over the past 30 years, health indicators in low-income countries remain alarming (WHO 2013b).

One challenge facing those working in public health involves the use of knowledge emanating from research. Recently, WHO African Region leaders again spoke about 
the "failure to apply all existing knowledge to improve people's health" (Kebede et al. 2014). A recent review of health research among member countries of the Economic Community of the West African States (ECOWAS) urged authorities to "facilitate the use of research results to drive health policy" (Sombié et al. 2013).

Several terms are used to refer to the process leading from the production of research-based knowledge to its use by practitioners and decision makers: knowledge translation, knowledge mobilization, knowledge implementation, knowledge transfer and exchange, etc. (Graham et al. 2006; McKibbon et al. 2010). It follows that each of the terms employed to describe the phenomenon that leads produced research results into practice is defined in many different ways throughout the scientific literature. Although a multitude of definitions exist, there has yet to be a consensus identifying the most appropriate one (Pentland et al. 2011). The term knowledge transfer is, however, the most commonly employed around the world (Graham et al. 2006) and is the one used throughout this article. The Fonds de recherche du Québec-Société et culture defines knowledge transfer as "all efforts made to ensure research activities and results are known and recognized... so they can be put to use by practice settings, decision-makers and the greater public, whether the process is interactive or not" (authors' translation) (FRQ-SC 2011, p. 9).

Use of research results can take several forms (Innvaer et al. 2002; Landry et al. 2001; Nutley et al. 2008; Weiss 1998), with the most well-documented being: (1) instrumental use (concrete changes in users' behaviours); (2) conceptual use (changes in users' understanding or attitudes; and (3) persuasive use (validation, support, or justification for a practice or decision).

Efforts to ensure practice settings and decision makers can benefit from scientific knowledge have led to the emergence of a new research field pursuing two objectives: (1) to evaluate the effectiveness of strategies to transfer scientific knowledge (outcomes analysis), and (2) to identify factors that might facilitate or inhibit the use of knowledge by users (process analysis).

\section{Outcomes analysis}

Transfer processes that are considered ineffective are passive strategies used singly, such as distribution of educational materials, audiovisual materials and electronic publications (Bero et al. 1998; Corrigan et al. 2001; Dobbins et al. 2009; Grimshaw et al. 2004). Audits and feedback sessions, involvement of opinion leaders, patientmediated interventions, conferences and use of practice guidelines produced mixed effects. Strategies shown to be effective are tailored targeted messages, combined use of multiple approaches, interactive small group meetings and computerized decision support (to help physicians with medical prescriptions). Grol and Grimshaw (2003) point out, however, that no transfer activity is effective enough to produce all types of change in all conditions. The effectiveness of strategies using multiple activities has been demonstrated (Grimshaw et al. 2004, 2006, 2012), although the literature does not report any observable relationship between number of strategies implemented and results obtained (Grimshaw et al. 2004, 2006, 2012; Walter et al. 2005).

\section{Process analysis}

Several conditions have been identified that can influence research results use (Dagenais et al. 2013b; Denis et al. 2002; Lysenko et al. 2014; Ouimet et al. 2006), having to do with the characteristics of: (1) the transfer strategies (e.g., interaction between the transfer agent and users, userfriendliness of the activity); (2) the transfer agent (e.g., attitude toward collaboration, communications skills); (3) the users (e.g. knowledge regarding the scientific culture, understanding of the scientific results presented); (4) the organizational context (e.g., change-resistant behaviours, availability of material and financial resources); and (5) the knowledge being transferred (e.g., relevance of the topic addressed, method of presenting the information).

An analysis of the scientific literature shows it deals primarily with interventions in high-income countries, such as Australia, Canada, the United States and the United Kingdom (Bero et al. 1998; Grimshaw et al. 2004, 2006; Van Eerd et al. 2011). To our knowledge, there has been no systematic review focusing specifically on interventions in low-income countries. Yet if we are concerned about equity, this is where the needs are greatest and where populations should benefit from more effective interventions. Our objective here is to provide a synthesis of scientific results to show the current state of research on knowledge transfer in low-income countries. Specifically, this review aims to describe the main findings of the studies included, the background and research methods used and the nature of the knowledge transfer activities.

\section{Methods}

We used the scoping review method (Arksey and O'Malley 2005), with its various stages. Unlike other systematic reviews, a scoping review does not include or exclude studies based on their research designs (Arksey and O'Malley 2005). Rather, those designs are taken into account in the data analysis. This approach allows for a comprehensive overview of all the topics, concepts and especially methodologies employed in the domain under study. 


\section{Identification of studies}

The following databases were consulted: MEDLINE and MEDLINE In-Process and Other Non-Indexed Citations, EMBASE, PsycINFO, Social Work Services Abstracts, Cochrane Database of Systematic Reviews, Cochrane Central Register of Controlled Trials, Cochrane Methodology Register, Database of Abstracts of Reviews of Effects, Health Technology Assessment Database, and NHS Economic Evaluation Database. The keywords used (English and French) were related to: (1) knowledge transfer and evidence-based practices; (2) the 36 low-income countries identified by the World Bank (2013); (3) intervention; and (4) empirical research. Table S1 in the appendix presents the strategy used to identify the studies in these different databases. In each database, our search covered the period from 1960 (when the concept of knowledge transfer first appeared) (Estabrooks et al. 2006) to May 2013.

\section{Selection and evaluation}

Articles were selected in two stages. First, we analysed the references obtained in the identification stage based on titles and abstracts. We then examined the complete texts of the articles retained. For both stages, we used the same inclusion criteria: (1) the study was conducted in a low-income country; (2) it focused on examining knowledge transfer processes and/or their outcomes; (3) it was empirical, i.e., based on data collection and analysis; and (4) it was published in English or French. The data from the articles retained after the second stage were extracted and analysed.

\section{Data extraction}

The analytical process consisted, first, of extracting as much information as possible to describe the studies retained. This process was based on the Grille descriptive des articles inclus dans une scoping study [Descriptive checklist for articles included in a scoping study] proposed by Malo and Robert (2011): country where the study was conducted; health issue(s) addressed; research design used; tools and instruments used to measure research use or its processes; transfer objectives pursued; transfer strategy/ strategies used; and actors involved in the transfer process.

Final data analyses

Once the data extracted, analyses of these information were performed to develop a picture of the studies' key results, in terms of strategies used, analysis of processes and types of use measured. The data were grouped by themes and then described for qualitative analysis and quantified whenever possible. Our analysis of the research designs was guided by the Mixed Method Appraisal Tool (MMAT) developed by Pluye et al. (2011). These analyses also provided a picture of the key results of the studies.

\section{Results}

The search identified 176 potentially relevant studies. After analysis of titles and abstracts, 63 studies were retained and their full texts reviewed in depth, resulting in a final pool of 28 studies. The flow diagram has been used (see Fig. 1). Table 1 presents a complete list of these references, the key elements analysed and the results derived from each. Each of these key elements is described in more details in this section.

Source and year of publication

More than half of the studies retained had been published in the past 4 years $(n=17,60.7 \%)$ and none before 2000 .

Research setting

\section{Low-income countries}

The studies were conducted in 8 of the 36 low-income countries $(22.2 \%)$ : Kenya $(n=10)$, Malawi $(n=5)$, Uganda $(n=3)$, Tanzania $(n=3)$, Bangladesh $(n=2)$, Nepal $(n=2)$, Burkina Faso $(n=1)$, Mali $(n=1)$ and Sierra Leone $(n=1)$.

\section{Health issue(s) addressed}

Four public health issues were targeted by the transfer strategies that were implemented (Fig. 2): (1) communicable diseases, such as malaria, HIV/AIDS and tuberculosis ( $n=12,42.9 \%$ ); (2) non-communicable diseases, such as anaemia ( $n=1,3.6 \%$ ); (3) health promotion, with respect to prevention measures, basic services, family planning and water treatment $(n=9,32.1 \%)$; and (4) health system improvement ( $n=6,21.4 \%)$.

\section{Research designs}

The designs varied depending on the transfer objectives. Studies looking only at processes used exclusively qualitative designs, whereas studies that used only quantitative designs were concerned solely with outcomes analysis. Mixed designs were used in studies looking at both outcomes and processes. Of note is the fact that: only half of the studies adequately identified the limitations of their research $(n=14,50 \%)$, a few listed them summarily $(n=5,17.9 \%)$ and nearly one-third did not mention them $(n=9,32.1 \%)$ (Table 2). 


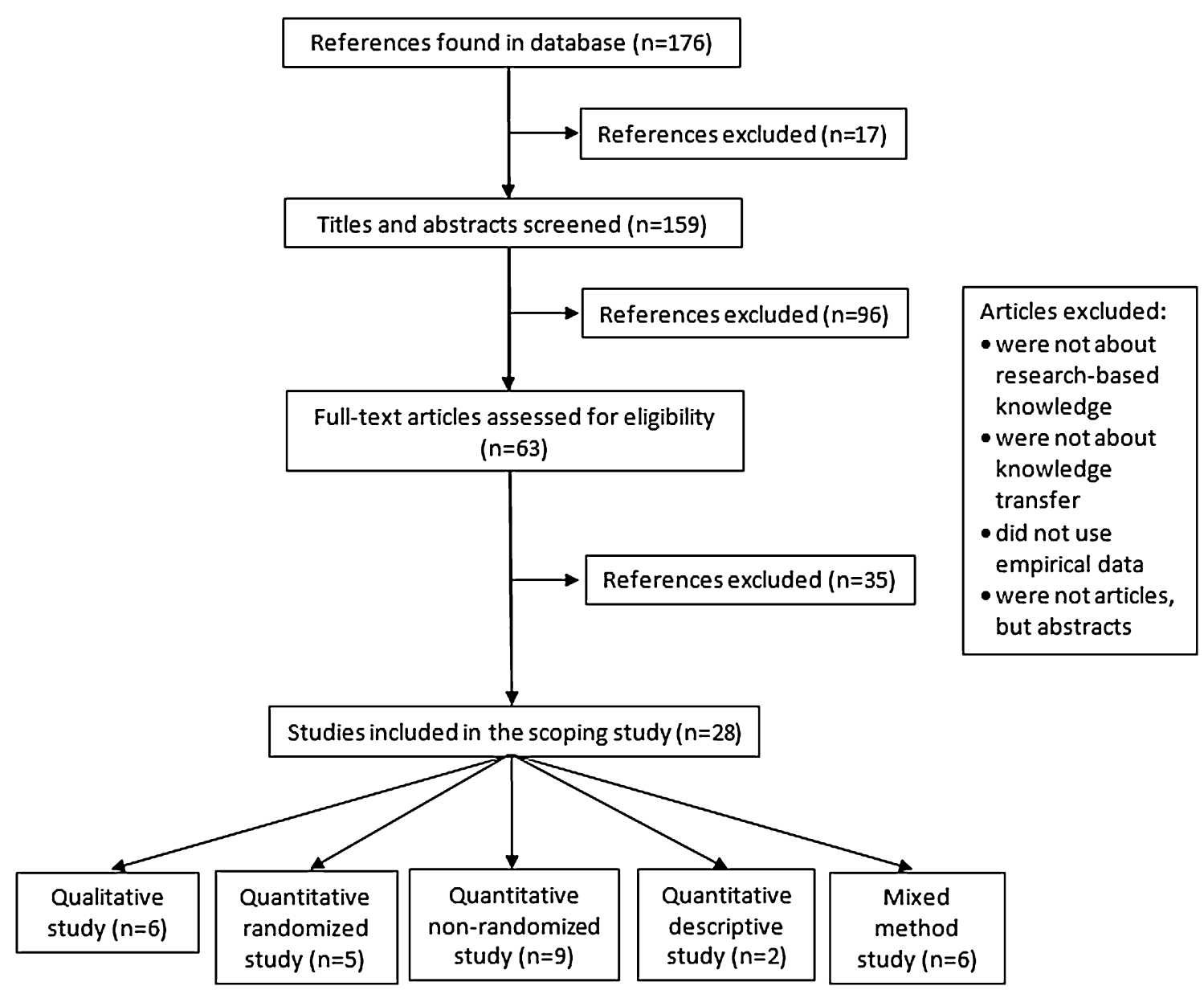

Fig. 1 PRISMA diagram depicting the flow of information through the different phases of scoping review process about research on knowledge transfer in low-income countries

\section{Evaluation objectives}

Half of the articles $(n=14)$ attempted to both evaluate the effectiveness of the transfer strategies implemented (outcomes analysis) and understand the processes that might explain the results obtained (process analysis). The studies that concentrated only on outcomes $(n=11)$ provided very little explanation regarding effectiveness; when explanations were offered $(n=4)$, they were brief and not the main focus of the analyses.

\section{Knowledge transfer strategies}

A wide variety of activities - more than 30-was noted; we grouped these into seven categories (Table 3). Training programs were the most frequently used activity $(n=26)$. Most of the studies evaluated strategies that used multiple activities, whether in training programs comprising several activities (e.g., demonstration and supervision sessions, workshops), or by combining more than one strategy (e.g., distribution of materials, public dissemination, local facilitators). Other, more innovative, strategies were also highlighted, such as artistic performances and games, and the use of specially adapted materials (e.g., picture books, photographs).

\section{Transfer agents involved}

It was usual for the same study to involve more than one type of transfer agent. Those most often mentioned were local facilitators $(n=14)$, including health professionals $(n=4)$, who received training and then, in turn, trained other less specialized professionals. There were also teachers who organized workshops with their students, and theatrical artists who gave performances and led the audience in group discussions $(n=4)$. Some local facilitators were also members of the community $(n=4)$, mothers, village chiefs or peer helpers, who were in charge of maintaining a product inventory and transmitting basic advice on the use of medications distributed. Last, several 


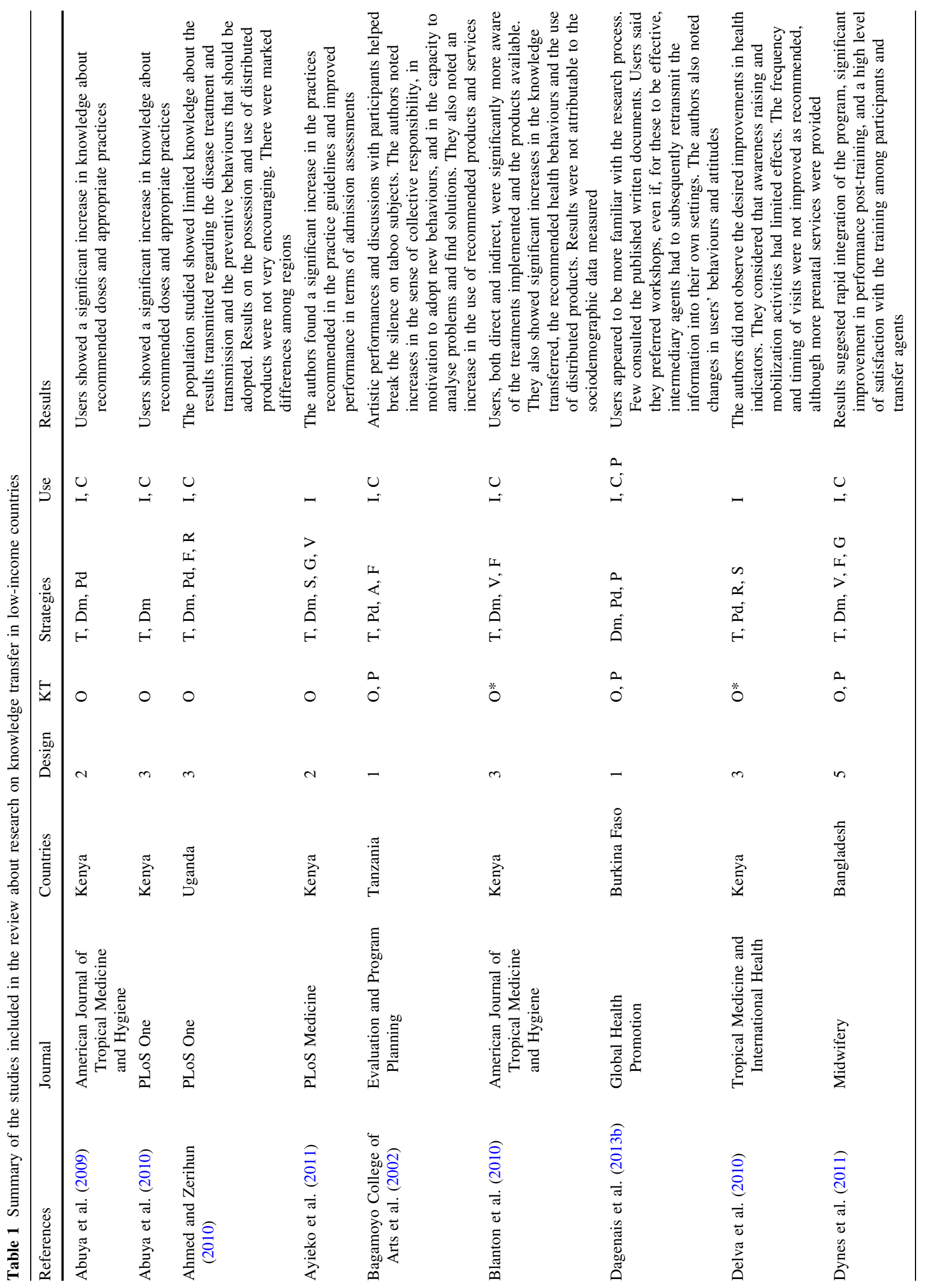




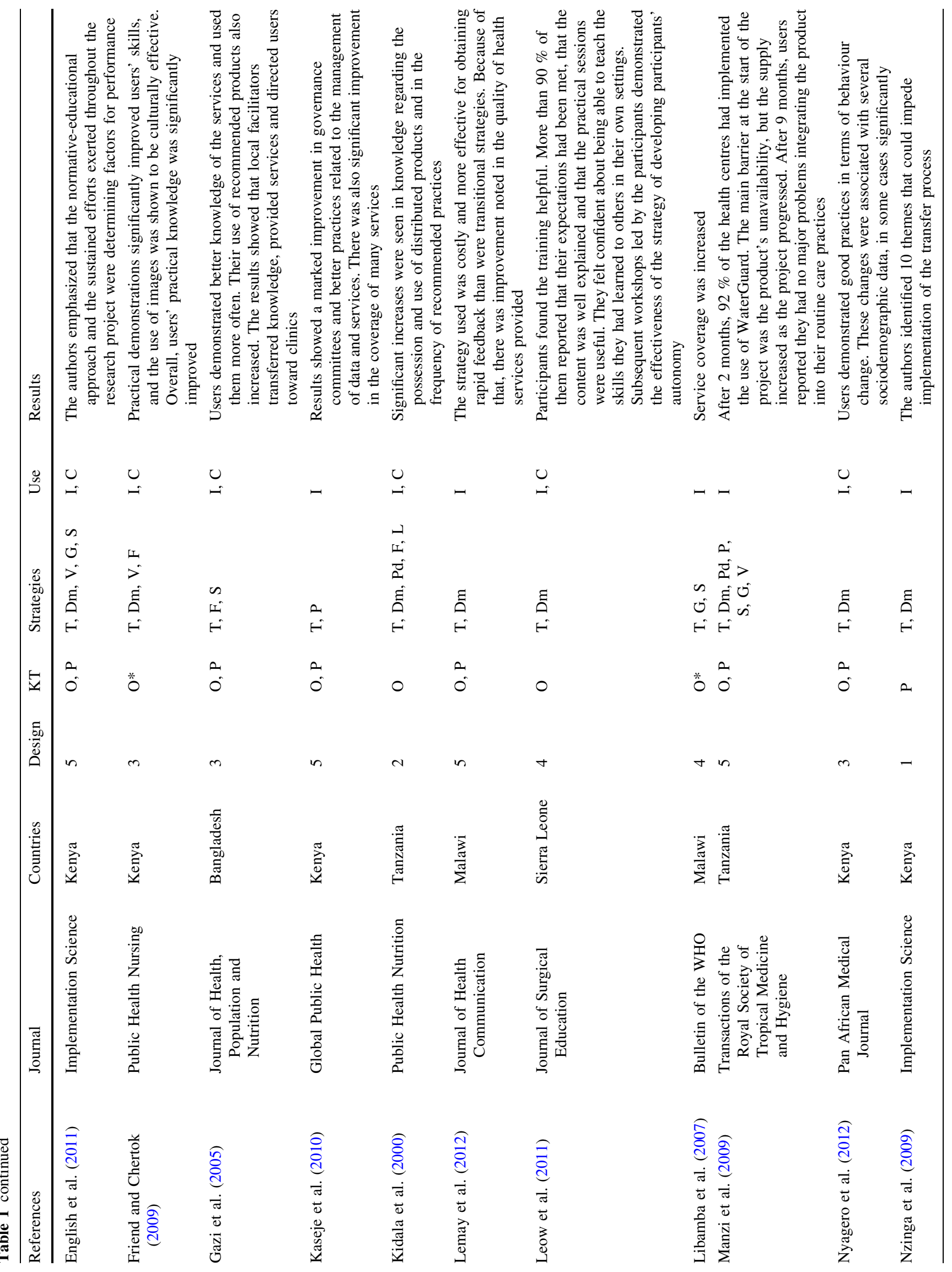




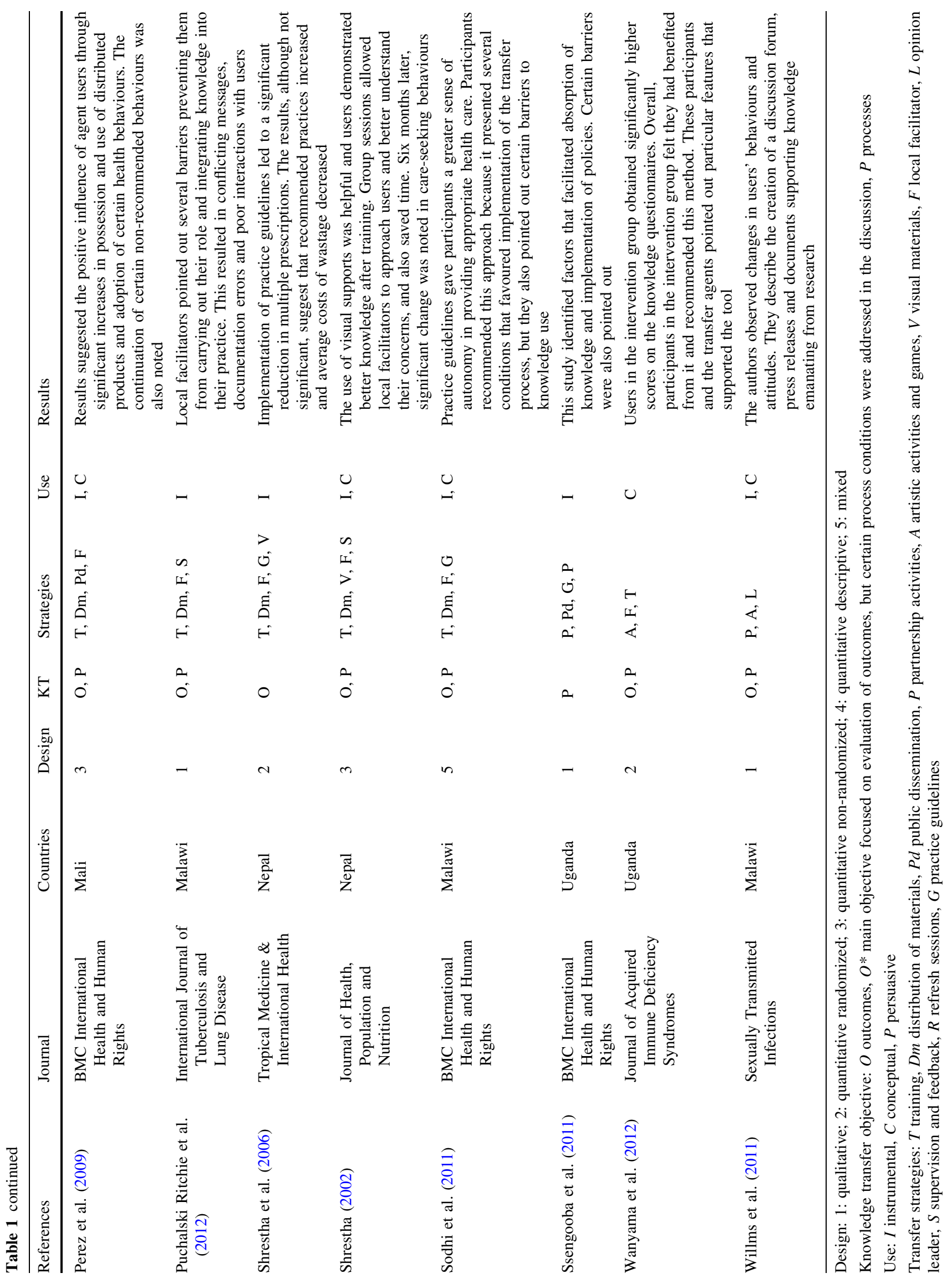


Fig. 2 Frequencies of public health issue(s) addressed in the studies included

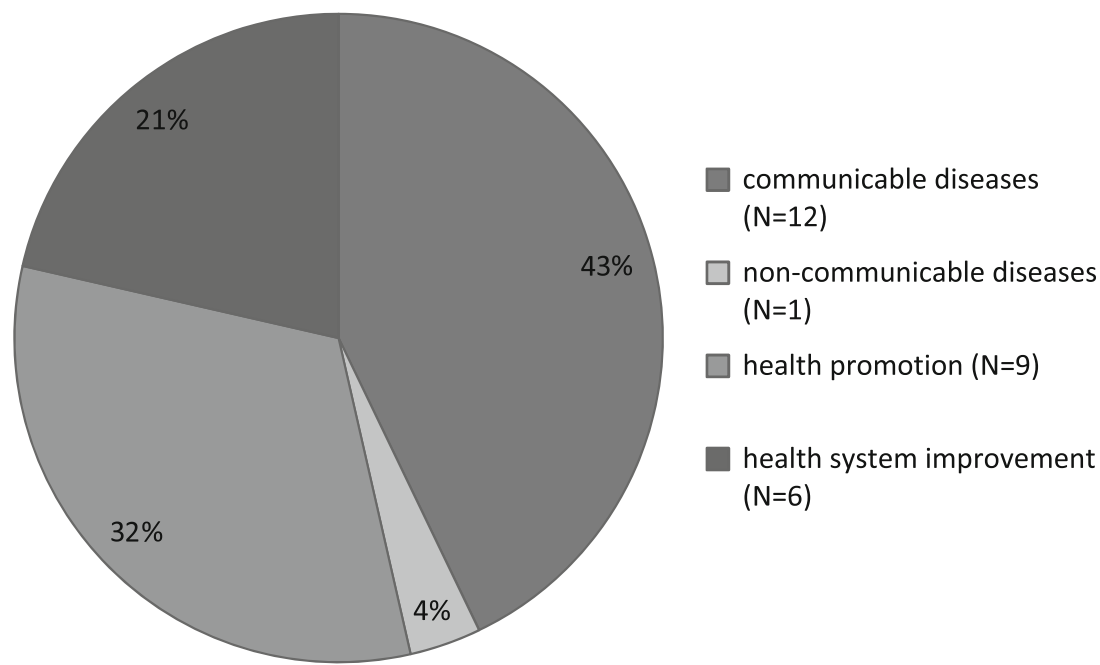

Table 2 Analysis of research designs in studies included in the review, inspired by the Mixed Method Appraisal Tool (Pluye et al. 2011)

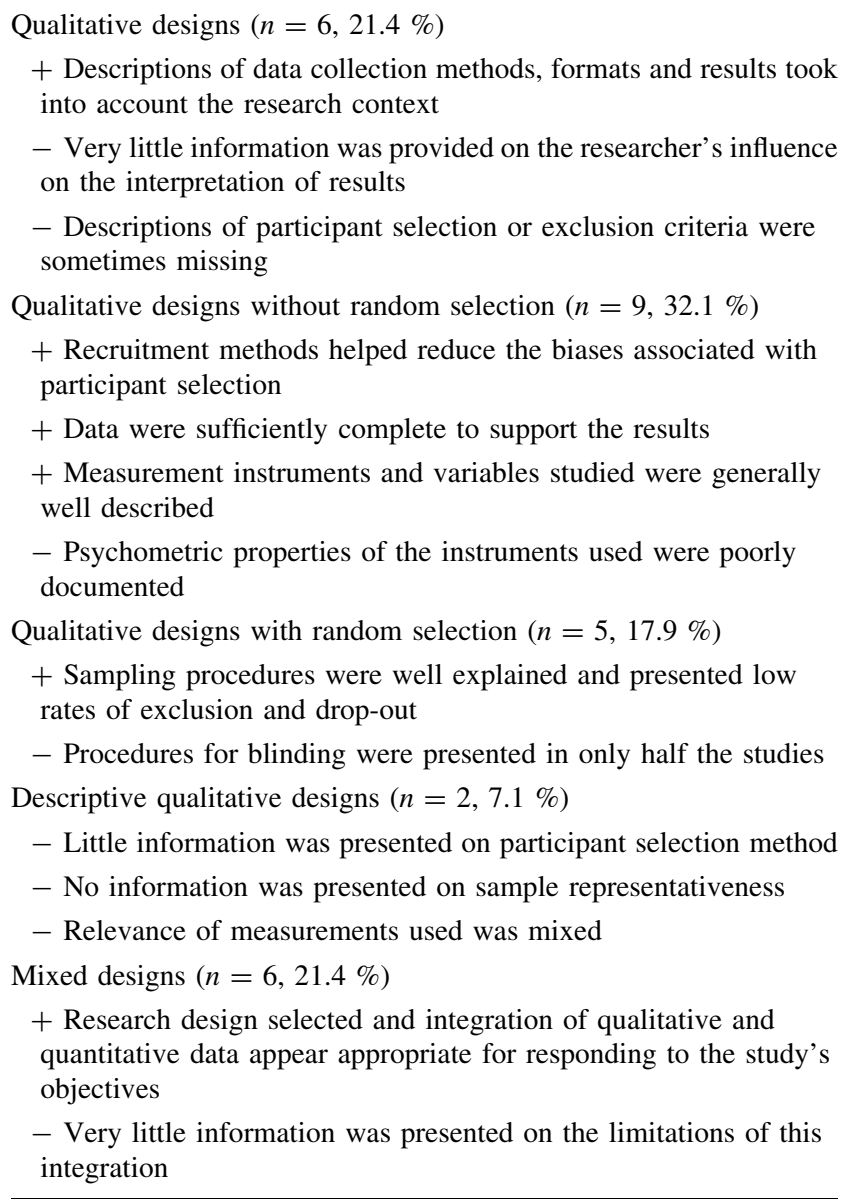

studies included instructors or trainers $(n=10)$ whose affiliations were rarely specified. The researchers $(n=6)$ represented only a small proportion of transfer agents.
Table 3 Knowledge transfer strategies used in the studies included

Training program $(n=26)$

Demonstrations and practical activities; seminars and workshops; supervision and feedback; refresh sessions; peer teaching; followup meetings; discussion sessions

Distribution of materials $(n=20)$

For implementation: bicycles, cellular telephones, practice guidelines and training manuals, teaching tools, wall posters in points of service

For use: medications, condoms, water containers, water purification sachets, seeds and seedlings, mosquito nets, health kits

Tailored materials: Comics, picture books, diagrams, photographs

Local facilitators $(n=13)$

Health professionals; community members

Public dissemination $(n=9)$

Awareness-raising activities; information sessions at points of service; health kiosks at markets; home visits; educational messages on health transmitted through the media and social networks; distribution of T-shirts with logos; scientific communications; policy briefs; press conferences

Partnership activities $(n=5)$

Digital platform; discussion forums and exchange network for partners; workshops

Artistic performances and games $(n=3)$

Theatre, dance, song, poetry; board games

Opinion leaders $(n=2)$

Religious leaders; village chiefs

\section{Target users}

The users most often targeted were patients/consumers ( $n=14$ ), primarily women (pregnant, nursing and/or with children under 5 years), but also young children and occasionally entire villages. In the category of health practitioners $(n=12)$, target users were mainly nurses, general practitioners and physicians in private practice. 
Political decision makers were much less often targeted as users $(n=3)$, and only one study targeted religious leaders.

\section{Results reported}

\section{Outcomes of transfer strategies}

Although a few authors pointed out certain barriers to knowledge use, which will be listed in the next section, overall, the outcomes were positive. Several were significant and involved three types of knowledge use. (1) Instrumental use $(n=27,96.4 \%)$. Several positive outcomes had to do with users' adoption of better health behaviours and increased use of essential products distributed (condoms, water purification sachets, seeds/ seedlings), increases in prenatal services provided, expansion of universal coverage and appropriateness of medical prescriptions. The results also reported on closer ties created between partners and greater practice autonomy among health professionals. (2) Conceptual use ( $n=18,64.3 \%$ ). Several articles reported positive changes in users' attitudes and knowledge, seen particularly in post-training questionnaires. There were also reports of improved knowledge on recommended treatments and risk factors associated with infectious diseases (e.g., HIV/AIDS, malaria), an increased sense of collective responsibility, a deeper understanding of users' health concerns, and the emergence of a sense of engagement and responsibility among administrative managers. In some articles, users reported feeling more familiar with the research process after participating in transfer activities, while others reported a high level of satisfaction with the activities being pursued. (3) Persuasive use ( $n=1$, $3.6 \%$ ). Only one article noted that knowledge transfer strategies provided users with research results to bolster arguments.

Only three articles (Ahmed and Zerihun 2010; Delva et al. 2010; Perez et al. 2009) reported inconclusive outcomes, such as limited knowledge about the results being transmitted regarding treatment of an illness, its transmission, and prevention behaviours that should be adopted. Another one (Ssengooba et al. 2011) reported mitigated results (of two interventions, one showed inconclusive results). Only one study reported negative result: the continuation of certain non-recommended behaviour (Perez et al. 2009).

Despite the encouraging results reported in most of the articles analysed, the overwhelming use of strategies employing multiple activities made it difficult to ascertain which outcomes were specific to each activity.

\section{Process analysis}

The analysis identified many conditions that facilitated or impeded users' adoption of new practices. These conditions fall into five categories (Table 4). Examples of the conditions are:

\section{Favourable conditions}

Creation of a rapid communication network (using SMS) and distribution of cellular telephones to allow local facilitators to obtain rapid feedback from program coordinators, to receive notifications when recommendations were changed, to share timely information with supervisors on specific medical questions or important events, and to maintain an up-to-date inventory of products distributed (Lemay et al. 2012); use of images (storytelling with scenarios) in ways that enabled people with low education to participate in problem-solving discussions (Shrestha 2002); artistic performances and audience discussions that helped break the silence on certain taboo subjects, especially HIV/AIDS illness and transmission (Bagamoyo College of Arts et al. 2002); and support to families and community recognition of women serving as depot-holders (women in the community who keep stock of commodities) (Gazi et al. 2005).

\section{Unfavourable conditions}

Difficulties encountered by some local facilitators in discussing family planning with participants, due to conservative cultural values that are in opposition to the recommended practices, and difficulties experienced by women in some isolated villages in trying to visit the community depot-holder or in getting to medical clinics when required for their health situation (Gazi et al. 2005); lack of adequate space and privacy to receive women and children in clinics and conduct medical interviews (Dynes et al. 2011; Puchalski Ritchie et al. 2012); lack of transportation, preventing lay health workers from conducting home visits, and lack of teaching materials, brochures and posters that would facilitate communication between frontline health workers and mothers (Puchalski Ritchie et al. 2012); and disruptions in the supply of WaterGuard, preventing users from integrating this product into their routine care practices, as recommended (Manzi et al. 2009).

\section{Discussion}

The main findings of our synthesis are as follows: The transfer agents were primarily trainers and practitioner 
Table 4 Conditions for knowledge utilization identified in the studies included in the review

\begin{tabular}{|c|c|}
\hline Conditions facilitating research results use & Conditions inhibiting research results use \\
\hline \multicolumn{2}{|l|}{ A strategy that... } \\
\hline Uses a participative approach & Does not involve continuing education sessions \\
\hline $\begin{array}{l}\text { Facilitates communication between agents and users, } \\
\text { and among the different partners }\end{array}$ & Provides training that is too brief or too intensive \\
\hline Involves local leaders & Does not promote communication among the different \\
\hline Has low costs & partners, agents and users, nor with those in charge of the \\
\hline Makes it possible to get rapid feedback & \\
\hline Is accessible (transportation) and flexible (schedule) & \\
\hline Involves a method of supervision & \\
\hline \multicolumn{2}{|l|}{ A transfer agent who... } \\
\hline Is highly devoted and committed to the population & Is not sufficiently knowledgeable \\
\hline Makes him/herself available to users & Lacks communication skills \\
\hline \multirow[t]{2}{*}{ Receives payment commensurate with the workload } & $\begin{array}{l}\text { Does not have the resources needed to carry out tasks } \\
\text { (limited means of transportation) }\end{array}$ \\
\hline & Is too poorly paid \\
\hline \multicolumn{2}{|l|}{ Users who... } \\
\hline See the benefits of using the knowledge that is transferred & Do not believe they need the knowledge being transferred \\
\hline $\begin{array}{l}\text { Present sufficient and accurate knowledge in relation } \\
\text { to the evidence provided }\end{array}$ & Lack knowledge on the different aspects of the disease \\
\hline \multirow[t]{5}{*}{ Recognize the value of the evidence presented } & $\begin{array}{l}\text { Have financial constraints and are not ready to pay the price for } \\
\text { essential products }\end{array}$ \\
\hline & $\begin{array}{l}\text { Have transportation constraints that make it difficult for them } \\
\text { to access services }\end{array}$ \\
\hline & $\begin{array}{l}\text { Have beliefs and cultural practices that are in contradiction } \\
\text { with the recommendations }\end{array}$ \\
\hline & Are resistant to change \\
\hline & Lack motivation \\
\hline \multicolumn{2}{|l|}{ An organizational setting that... } \\
\hline Facilitates the delegation of tasks among professionals & Lacks the necessary resources: space, products, and teaching materials \\
\hline $\begin{array}{l}\text { Fosters communication among partners, agents, and organizers } \\
\text { of the strategies }\end{array}$ & Provides inadequate services and incomplete information and education \\
\hline $\begin{array}{l}\text { Value transfer activities and support agents in their activities } \\
\text { (social acceptability) }\end{array}$ & $\begin{array}{l}\text { Does not understand the community's involvement and participation } \\
\text { in the transfer process }\end{array}$ \\
\hline \multirow{3}{*}{$\begin{array}{l}\text { Is able to receive and absorb user demands to deliver products } \\
\text { recommended by evidence (condoms, vaccinations, } \\
\text { primary care services, etc.) }\end{array}$} & Has a high staff turnover rate \\
\hline & Does not provide the support required for supervision \\
\hline & $\begin{array}{l}\text { Does not enable users to access the essential products recommended } \\
\text { by research results }\end{array}$ \\
\hline \multicolumn{2}{|l|}{ Knowledge that... } \\
\hline Is tailored to the context & Is too complicated to understand \\
\hline $\begin{array}{l}\text { Is transmitted in ways that respect users' level of education } \\
\text { Is available }\end{array}$ & Is not available \\
\hline
\end{tabular}

experts, and the users were mostly health professionals and consumers of health services (mothers, young children, village populations). All the transfer strategies studied used multiple activities, with the primary activities being training, distribution of materials and local facilitators. The studies mainly used quantitative designs, and measures of instrumental utilization were the most often used; however, the psychometric properties of the evaluation instruments were rarely reported. The primary outcomes of the evaluated strategies were increases in knowledge being transferred to health professionals and greater use by the population of recommended essential products. 
Methodological shortcomings

The articles consulted provided little or no information that would normally be used to judge methodological quality, such as on the psychometric properties of instruments, blinding procedures, the researchers' influence on the interpretation of results and the degree of representativeness of the sample. Results obtained under those circumstances must be interpreted with caution. This situation has also been reported in systematic reviews on knowledge transfer in high-income countries (Dagenais et al. 2013a; Grimshaw et al. 2004, 2006, 2012; Van Eerd et al. 2011).

\section{Relevance of topics}

The marked preoccupation with the treatment of communicable diseases in nursing or pregnant women and in young children coincides with these countries' priorities (GBD 2013 Mortality and Causes of Death Collaborators 2015).

Effective and innovative transfer strategies

The articles evaluated transfer strategies whose effectiveness has been demonstrated in other contexts. For example, many studies evaluated strategies involving multiple activities, such as training programs (Grimshaw et al. 2004, 2006,2012 ) and the combined use of practice guidelines, distribution of materials and other transfer activities. These strategies have been shown to be effective in high-income countries (Corrigan et al. 2001; Grimshaw et al. 2004). The same is true with respect to the effectiveness of supervision and feedback sessions as well as of partnership activities bringing together transfer agents and potential users (Grol and Grimshaw 2003).

Some innovative strategies (see Table 3) identified in our review are rarely or never seen in studies conducted in high-income countries, and their effectiveness remains to be demonstrated. Nevertheless, they are of interest because they have many commonalities with recommendations coming out of research in high-income countries: adapting presentation methods to users' education level, using accessible language and creating direct links between transfer agents and users (Dagenais et al. 2008; Davies et al. 2010; Gagliardi et al. 2008; Ouimet et al. 2006).

Divergences from scientific literature from the high income countries (HIC)

The studies generally employed strategies involving multiple activities, but rarely explained this choice. Moreover, even though these strategies have been shown to be effective in low-income countries, the scientific literature does not report any clear relationship between the number of activities implemented and the outcomes achieved; the same is true for the literature on high-income countries (Grimshaw et al. 2004, 2006, 2012; Walter et al. 2005). Surprisingly, the articles analysed also present very few strategies using tailored targeted messages, which are known to be effective (Dobbins et al. 2009). These divergences may be due to the difficulty in accessing scientific results experienced by those engaged in knowledge transfer in low-income countries (Kebede et al. 2014). As well, these countries' resource limitations may inhibit implementation of sometimes costly strategies.

Some strategies shown to be ineffective in high-income countries (Grimshaw et al. 2004) were nevertheless used in the studies reported in the articles we reviewed: awarenessraising activities, public information sessions and scientific publications. However, these were always combined with other activities that were shown to be effective or favourable to knowledge use. As such, the transfer strategies chosen in the articles were consistent with available evidence, both in terms of outcomes evaluation or process analysis.

\section{Foreseeable outcomes}

It is not surprising that the transfer strategies reported in the articles were effective, as their characteristics are in keeping with evidence. For example, training programs, which were widely used, favour active participation (group discussions, practical activities) and are tailored to education levels (support and visual materials). Even though little data are available on the more innovative strategies used (artistic performances, games, visual materials), these are inherently favourable to knowledge use by virtue of their characteristics. The use of images has been proven to be culturally effective and appreciated by both users and transfer agents. The same is true for workshops, training programs, practical activities and group discussions, even if these require more time on all sides. The effectiveness of practice guidelines has been mixed, as reported in the scientific literature in other contexts (Grol and Grimshaw 2003). Finally, the limited outcomes of certain activities, such as consulting written documentation and awarenessraising activities - the so-called passive activities-are similar to those of activities described elsewhere (Bero et al. 1998; Grimshaw et al. 2004).

Observable measures of use

The omnipresence of instrumental use is consistent with results reported by others (Dagenais et al. 2013a; Malo and Robert 2011). This trend may be due to the observable nature of instrumental use, which favours its measurement. 
The predominance of conceptual use in the articles analysed is, however, more surprising, and may be due to the strong presence of training programs, which are essentially aimed at increasing users' knowledge. The near-absence of persuasive use has also been reported in other contexts (Dagenais et al. 2013a; Malo and Robert 2011). This may be due to the difficulty of observing and evaluating these types of outcomes, which are sometimes more diffused, or to a possible lack of instruments developed for this purpose, or to a scientific culture that is not very sensitive to this type of measure and its impacts.

\section{Known transfer processes}

Several conditions for knowledge use reported in the articles analysed are similar to those observed in other contexts (Dagenais and Janosz 2008; Davies et al. 2010; Gagliardi et al. 2008). Examples include strategies that foster communication between agents and users, organizations that value knowledge transfer activities and have the resources to implement them, and a presentation method tailored to the audience. Organizations' lack of resources to implement recommended transfer strategies was identified as a condition impeding knowledge use.

\section{Conditions for use specific to low-income countries}

Examples include the frequent use of local facilitators from the community to compensate for the lack of qualified personnel. In most cases, these transfer agents are health care professionals in general or local level who receive training on a specific topic. Examples also included training programs that are sometimes very brief to minimize health professionals' time away from their work. Also noted were careful selection of training sites and points of service to maximize accessibility, and accommodations made to facilitate transportation for the population or to reduce the geographic distance between professionals on the ground and their supervisors. Using artistic performances (theatre, songs, poems) to transmit information about diseases also showed concern for adapting to people's beliefs and traditions (Loewenson et al. 2014). Visual tools were sometimes created to accommodate to the low education levels of the populations studied. Targeting and involving important persons was another strategy used to enhance the social acceptability of the knowledge being transferred to potential users. These strategies' effectiveness is consistent with results from action research on factors that facilitate knowledge transfer and application (Estabrooks et al. 2003).

In these low-income countries, careful attention appears to have been given to adapting transfer strategies to their specific contexts, which is seen much less clearly in the scientific literature on other countries. Given the seriousness of the public health issues in these low-income countries and the resource constraints they face, adapting transfer strategies to these contexts seems to be a necessity, and it is encouraging to observe that many studies have made this a priority.

\section{Limitations of the study}

Even with the systematic and retraceable process of a scoping review, the present study has certain limitations. First, only articles published in English and in French were consulted, such that articles written in the languages of certain low-income countries may have been excluded de facto. We also limited our search to scientific journals, whereas other relevant publications may have been available in the grey literature. Finally, it should be mentioned that another search strategy with slightly different inclusion criteria would have led to different research material and different conclusions.

\section{Conclusion}

As in most studies on global health interventions or on health systems and policies, we believe it would be beneficial for researchers to examine and analyse more closely the characteristics of the context (cultural, political and economic) within which research is conducted and transfer activities implemented. It is also recommended, whenever possible, to use measurement instruments whose psychometric properties have been demonstrated. In fact, much more methodological development is required to evaluate knowledge transfer in low-income countries. Our results highlight the need for systematic evaluation of the conditions for research results use in the settings where transfer activities occur, to identify strategies that specifically target barriers inherent to the context, according to the five categories of conditions presented in Table 4. This step is likely to improve outcomes and reduce costs associated with using multiple strategies, some of which are less relevant.

While there is a need to increase the quantity and quality of research on transfer activities, there is also a strong need for more knowledge transfer interventions in low-income countries.

Acknowledgments This study was conducted as part of the first author's doctoral training in clinical psychology. The candidate received financial support from Équipe RENARD, a research team studying knowledge transfer, which is led by Christian Dagenais. Valéry Ridde holds a CIHR-funded Research Chair in Applied Public Health (CPP-137901). We thank the Canadian Institutes of Health Research (CIHR), which funded part of the study (ROH-115213).

Open Access This article is distributed under the terms of the Creative Commons Attribution 4.0 International License 
(http://creativecommons.org/licenses/by/4.0/), which permits unrestricted use, distribution, and reproduction in any medium, provided you give appropriate credit to the original author(s) and the source, provide a link to the Creative Commons license, and indicate if changes were made.

\section{References}

Abuya T, Fegan G, Rowa Y, Karisa B, Ochola S, Mutemi W, Marsh V (2009) Impact of ministry of health interventions on private medicine retailer knowledge and practices on anti-malarial treatment in Kenya. Am J Trop Med Hyg 80(6):905-913. http://www.ajtmh.org/content/80/6/905.short. Accessed 17 July 2015

Abuya TO, Fegan G, Amin AA, Akhwale WS, Noor AM, Snow RW, Marsh V (2010) Evaluating different dimensions of programme effectiveness for private medicine retailer malaria control interventions in Kenya. PLoS One 5(1):e8937. doi:10.1371/ journal.pone.0008937

Ahmed SM, Zerihun A (2010) Possession and usage of insecticidal bed nets among the people of Uganda: is BRAC Uganda health programme pursuing a pro-poor path? PLoS One 5(9):e12660. doi:10.1371/journal.pone.0012660

Allen LH, Gillespie SR (2001) What works? A review of the efficacy and effectiveness of nutrition interventions. ACC/SCN Geneva in collaboration with the Asian Development Bank, Manila. http://www.ifpri.org/sites/default/files/publications/whatworks. pdf. Accessed 6 Mar 2015

Arksey H, O'Malley L (2005) Scoping studies: towards a methodological framework. Int J Soc Res Methodol 8(1):19-32. doi:10. 1080/1364557032000119616

Ayieko P, Ntoburi S, Wagai J, Opondo C, Opiyo N, Migiro S, Wamae A, Mogoa W, Were F, Wasunna A, Fegan G, Irimu G, English M (2011) A multifaceted intervention to implement guidelines and improve admission paediatric care in Kenyan district hospitals: a cluster randomised trial. PLoS Med 8(4):e1001018. doi:10.1371/ journal.pmed.1001018

Bagamoyo College of Arts, Tanzania Theatre Centre, Mabala R, Allen KB (2002) Participatory action research on HIV/AIDS through a popular theatre approach in Tanzania. Eval Program Plann 25(4):333-339. doi:10.1016/S0149-7189(02)00044-7

Bero LA, Grilli R, Grimshaw JM, Harvey E, Oxman AD, Thomson MA (1998) Closing the gap between research and practice: an overview of systematic reviews of interventions to promote the implementation of research findings. BMJ 317(7156):465-468. doi: $10.1136 / \mathrm{bmj} .317 .7156 .465$

Blanton E, Ombeki S, Oluoch GO, Mwaki A, Wannemuehler K, Quick R (2010) Evaluation of the role of school children in the promotion of point-of-use water treatment and handwashing in schools and households-Nyanza Province, Western Kenya, 2007. Am J Trop Med Hyg 82(4):664-671. doi:10.4269/ajtmh. 2010.09-0422

Corrigan PW, Steiner L, McCracken SG, Blaser B, Barr M (2001) Strategies for disseminating evidence-based practices to staff who treat people with serious mental illness. Psychiatr Serv 52(12):1598-1606. doi:10.1176/appi.ps.52.12.1598

Dagenais C, Janosz M (2008) Étude des besoins des chercheurs de l'université en matière de transfert des connaissances issues de la recherche [Report on the needs of the University's researchers with regard to transferring knowledge emanating from research]. Regroupement VINCI, Bureau Recherche-DéveloppementValorisation. University of Montreal. https://www.recherche. umontreal.ca/fileadmin/user_upload/Valorisation_de_la_recherche/ rapport_final_vinci.pdf. Accessed 6 Mar 2015
Dagenais C, Janosz M, Abrami P, Bernard R, Lysenko L (2008) Intégrer les informations issues de la recherche aux pratiques professionnelles des enseignants et des gestionnaires dans les écoles : Pour un modèle de transfert des connaissances adapté au domaine de l'éducation. [Integrating research results into the professional practices of teachers and managers in schools: a knowledge transfer model adapted to education]. Report prepared for the Canadian Council on Learning, Ottawa. http:// www.ccl-cca.ca/pdfs/FundedResearch/DagenaisFRFinal.pdf. Accessed 6 Mar 2015

Dagenais C, Malo M, Robert E, Ouimet M, Berthelette D, Ridde V (2013a) Knowledge transfer on complex social interventions in public health: a scoping study. PLoS One 8(12):e80233. doi:10. 1371/journal.pone.0080233

Dagenais C, Queuille L, Ridde V (2013b) Evaluation of a knowledge transfer strategy from a user fee exemption program for vulnerable populations in Burkina Faso. Glob Health Promot 20(Suppl 1):70-79. doi:10.1177/1757975912462416

Davies HTO, Nutley SM, Walter I (2010) Using evidence: how social research could be better used to improve public service performance. In: Walshe K, Harvey G, Jas P (eds) Connecting knowledge and performance in public services: from knowing to doing. Cambridge University Press, New York, pp 199-225

Delva W, Yard E, Luchters S, Chersich MF, Muigai E, Oyier V, Termmerman M (2010) A Safe Motherhood project in Kenya: assessment of antenatal attendance, service provision and implications for PMTCT. Trop Med Int Health 15(5):584-591. doi:10.1111/j.1365-3156.2010.02499.x

Denis JL, Hébert Y, Langley A, Lozeau D, Trottier LH (2002) Explaining diffusion patterns for complex health care innovations. Health Care Manage Rev 27(3):60-73. http://www.ncbi. nlm.nih.gov/pubmed/12146784. Accessed 6 Mar 2015

Dobbins M, Robeson P, Ciliska D, Hanna S, Cameron R, O'Mara L, DeCorby K, Mercer S (2009) A description of a knowledge broker role implemented as part of a randomized controlled trial evaluating three knowledge translation strategies. Implement Sci 4(23):1-9. doi:10.1186/1748-5908-4-23

Dynes M, Rahman A, Beck D, Moran A, Rahman A, Pervin J, Yunus M, Rashid MH, Gazi T, Kanti Biswas K, Buffington S, Patterson JM, Sibley L (2011) Home-based life saving skills in Matlab, Bangladesh: a process evaluation of a community-based maternal child health programme. Midwifery 27(1):15-22. doi:10. 1016/j.midw.2009.07.009

English M, Nzinga J, Mbindyo P, Ayieko P, Irimu G, Mbaabu L (2011) Explaining the effects of a multifaceted intervention to improve inpatient care in rural Kenyan hospitals-interpretation based on retrospective examination of data from participant observation, quantitative and qualitative studies. Implement Sci 6(124):1-12. doi:10.1186/1748-5908-6-124

Estabrooks CA, Floyd JA, O'Leary KA, Gushta M (2003) Individual determinants of research utilization: a systematic review. J Adv Nurs 43(5):506-520. doi:10.1046/j.1365-2648.2003.02748.x

Estabrooks CA, Thompson DS, Lovely JJ, Hofmeyer A (2006) A guide to knowledge translation theory. J Contin Educ Health Prof 26(1):25-36. doi: $10.1002 / \mathrm{chp} .48$

Friend D, Chertok IRA (2009) Evaluation of an educational intervention to promote breast pump use among women with infants in a special care nursery in Kenya. Public Health Nurs 26(4):339-345. doi:10.111/j.1525.1446.2009.00788.x

FRQ-SC (2011) Plan d'action en matière de transfert de connaissances 2011-2014. [Knowledge transfer action plan 2011-2014] Fonds de recherche québécois-Société et culture. Québec. http://www.frqsc.gouv.qc.ca/upload/publications-fqrsc/fichiers/ publication_52.pdf. Accessed 6 Mar 2015

Gagliardi AR, Fraser N, Wright FC, Lemieux-Charles L, Davis D (2008) Fostering knowledge exchange between researchers and 
decision-makers: exploring the effectiveness of a mixed-methods approach. Health Policy 86(1):53-63. doi:10.1016/j.healthpol. 2007.09.002

Gazi R, Mercer A, Khatun J, Islam Z (2005) Effectiveness of depotholders introduced in urban areas: evidence from a pilot in Bangladesh. J Health Popul Nutr 23(4):377-387. http://www. bioline.org.br/pdf?hn05050. Accessed 6 Mar 2015

GBD 2013, Mortality and Causes of Death Collaborators (2015) Global, regional, and national age-sex specific all-cause and cause-specific mortality for 240 causes of death, 1990-2013: a systematic analysis for the Global Burden of Disease Study 2013. Lancet 385:117-171. doi:10.1016/S0140-6736(14)616822

Graham ID, Logan J, Harrison MB, Straus SE, Tetroe J, Caswell W, Robinson N (2006) Lost in knowledge translation: time for a map? J Contin Educ Health Prof 26(1):13-24. doi:10.1002/chp. 47

Grimshaw JM, Thomas RE, MacLennan G, Fraser G, Ramsay CR, Vale L, Whitty P, Eccles MP, Matowe L, Shirran L, Wensing M, Dijkstra R, Donaldson C (2004) Effectiveness and efficiency of guideline dissemination and implementation strategies. Health Technol Assess 8(6):iii-iv, 1-72. doi:10.3310/hta8060

Grimshaw JM, Eccles MP, Thomas R, MacLennan G, Ramsay C, Fraser C, Vale K (2006) Toward evidence-based quality improvement. Evidence (and its limitations) of the effectiveness of guideline dissemination and implementation strategies 1966-1998. J Gen Intern Med 21(Suppl 2):14-20. doi:10.1111/ j.1525-1497.2006.00357.x

Grimshaw JM, Eccles MP, Lavis JN, Hill SJ, Squires JE (2012) Knowledge translation of research findings. Implement Sci 7:50. doi:10.1186/1748-5908-7-50

Grol R, Grimshaw J (2003) From best evidence to best practice: effective implementation of change in patients' care. Lancet 362(9391):1225-1230. doi:10.1016/S0140-6736(03)14546-1

Innvaer S, Vist G, Trommald M, Oxman A (2002) Health policymakers' perceptions of their use of evidence: a systematic review. J Health Serv Res Policy 7(4):239-244. doi:10.1258/ 135581902320432778

Kaseje D, Olayo R, Musita C, Oindo CO, Wafula C, Muga R (2010) Evidence-based dialogue with communities for district health systems' performance improvement. Glob Public Health 5(6):595-610. doi:10.1080/17441690903418969

Kebede D, Zielinski C, Mbondji PE, Piexoto M, Kouvividila W, Lusamba-Dikassa PS (2014) The way forward-narrowing the knowledge gap in the sub-Saharan Africa to strengthen health systems. J R Soc Med 107(15):10-12. doi:10.1177/ 0141076813512818

Kidala D, Greiner T, Gebre-Medhin M (2000) Five-year follow-up of a food-based vitamin A intervention in Tanzania. Public Health Nutr 3(4):425-431. http://journals.cambridge.org/action/ displayAbstract?fromPage $=$ online $\&$ aid $=556224 \&$ file $\mathrm{Id}=$ S1368980000000495. Accessed 17 July 2015

Landry R, Amara N, Lamari M (2001) Utilization of social science research in Canada. Res Policy 30(2):333-349. doi:10.1016/ S0048-7333(00)00081-0

Lemay NV, Sullivan T, Jumbe B, Perry CP (2012) Reaching remote health workers in Malawi: baseline assessment of a pilot mHealth intervention. J Health Commun 17(Suppl 1):105-117. doi:10.1080/10810730.2011.649106

Leow JJ, Groen RS, Kamara TB, Dumbuya SS, Kingham TP, Daoh KS, Kushner AL (2011) Teaching emergency and essential surgical care in Sierra Leone: a model for low income countries. J Surg Educ 68(5):393-396. doi:10.1016/j.jsurg.2011.05.012

Levine R, What Works Working Group (2004) Millions saved. Proven successes in global health. Center for Global Development, Washington, DC
Libamba E, Makombe SD, Harries AD, Schouten EJ, Yu JK, Pasulani O, Mhango E, Aberle-Grasse J, Hochgesang M, Limbambala E, Lungu D (2007) Malawi's contribution to "3 by 5": achievements and challenges. Bull World Health Organ 85(2):156-160. doi:10.2471/BLT.05.033688

Loewenson R, Laurell AC, Hogstedt C, D’Ambruoso L, Shroff Z (2014) Participatory action research in health systems: a methods reader. TARSC, AHPSR, WHO, IDRC Canada, EQUINET, Harare. http://www.equinetafrica.org/bibl/docs/PAR\% 20Methods\%20Reader2014\%20for\%20web.pdf. Accessed 6 Mar 2015

Lysenko LV, Abrami PC, Bernard RB, Dagenais C, Janosz M (2014) Educational research in educational practice: predictors of use. Can J Educ 37(2). http://journals.sfu.ca/cje/index.php/cje-rce/ article/view/1477. Accessed 17 July 2015

Malo M, Robert E (2011) Proposition: canevas pour une scoping study (Unpublished manuscript)

Manzi F, Schellenberg J, Hamis Y, Mushi AK, Shirima K, Mwita A, Simba A, Rusibamayila N, Kitambi M, Tanner M, Alonso P, Mshinda H, Schellenberg D (2009) Intermittent preventive treatment for malaria and anaemia control in Tanzanian infants: the development and implementation of a public health strategy. Trans R Soc Trop Med Hyg 103(1):79-86. doi:10.1016/j.trstmh. 2008.08.014

McKibbon KA, Lokker C, Wilczynski NL, Ciliska D, Dobbins M, Davis DA, Haynes RB, Straus SE (2010) A cross-sectional study of the number and frequency of terms used to refer to knowledge translation in a body of health literature in 2006: a Tower of Babel? Implement Sci 5(16):1-11. doi:10.1186/1748-5908-5-16

Nutley S, Jung T, Walter I (2008) The many forms of researchinformed practice: a framework for mapping diversity. Camb J Educ 38(1):53-71. doi:10.1080/03057640801889980

Nyagero J, Wangila S, Kutai V, Olango S (2012) Behaviour change and associated factors among female sex workers in Kenya. Pan Afr Med J 13(1):1-6. http://www.ncbi.nlm.nih.gov/pmc/articles/ PMC3589252/. Accessed 17 July 2015

Nzinga J, Mbindyo P, Mbaabu L, Warira A, English M (2009) Documenting the experiences of health workers expected to implement guidelines during an intervention study in Kenyan hospitals. Implement Sci 4:44. doi:10.1186/1748-5908-4-44. Accessed 17 July 2015

Ouimet M, Landry R, Amara N, Belkhodja O (2006) What factors induce health care decision-makers to use clinical guidelines? Evidence from provincial health ministries, regional health authorities and hospitals in Canada. Soc Sci Med 62(4):964-976. doi:10.1016/j.socscimed.2005.06.040

Pentland D, Forsyth K, Maciver D, Walsh M, Murray R, Irvine L, Sikora S (2011) Key characteristics of knowledge transfer and exchange in healthcare: integrative literature review. J Adv Nurs 67(7):1408-1425. doi:10.1111/j.1365-2648.2011.05631.x

Perez F, Ba H, Dastagire SG, Altmann M (2009) The role of community health workers in improving child health programmes in Mali. BMC Int Health Hum Rights 9:28. doi:10. 1186/1472-698X-9-28. Accessed 17 July 2015

Peters DH, El-Saharty S, Siadat B, Janovsky K, Vujicic M (eds) (2009) Improving health service delivery in developing countries: from evidence to action. World Bank, Washington, DC. https://openknowledge.worldbank.org/handle/10986/12335. Accessed 6 Mar 2015

Pluye P, Robert E, Cargo M, Bartlett G, O'Cathain A, Griffiths F, Boardman F, Gagnon MP, Rousseau MC (2011) Proposal: a mixed methods appraisal tool for systematic mixed studies. Archived by WebCite ${ }^{\circledR}$ at http://www.webcitation.org/ 5tTRTc9yJ. Accessed on 6 Mar 2015

Puchalski Ritchie LM, van Lettow M, Barnsley J, Chan AK, Joshua M, Martiniuk AL, Schull MJ, Zwarenstein M (2012) Evaluation 
of lay health workers' needs to effectively support antituberculosis treatment adherence in Malawi. Int J Tuberc Lung Dis 16(11):1492-1497. doi:10.5588/ijtld.12.0206

Shrestha S (2002) Increasing contraceptive acceptance through empowerment of female community health volunteers in rural Nepal. J Health Popul Nutr 20(2):156-165. http://www.jhpn.net/ index.php/jhpn/article/view/140/135. Accessed 6 Mar 2015

Shrestha N, Samir KC, Baltussen R, Kafle KK, Bishai D, Niessen L (2006) Practical approach to lung health in Nepal: better prescribing and reduction of cost. Trop Med Int Health 11(5):765-772. doi:10.1111/j.1365-3156.2006.01599.x

Sodhi S, Banda H, Kathyola D, Burciul B, Thompson S, Joshua M, Bateman E, Fairall L, Martiniuk A, Cornick R, Faris G, Draper B, Mondiwa M, Katengeza E, Sanudi L, Zwarenstein M, Schull MJ (2011) Evaluating a streamlined clinical tool and educational outreach intervention for health care workers in Malawi: the PALM PLUS case study. BMC Int Health Hum Rights 11(Suppl 2):S11. doi:10.1186/1472-698X-11-S2-S11. Accessed 17 Jul 2015

Sombié I, Aidam J, Konaté B, Somé TD, Kambou SS (2013) The state of the research for health environment in the ministries of health of the Economic Community of the West African States (ECOWAS). Health Res Policy Syst 11:35. doi:10.1186/1478-4505-11-35

Ssengooba F, Atuyambe L, Kiwanuka SN, Puvanachandra P, Glass N, Hyder AA (2011) Research translation to inform national health policies: learning from multiple perspectives in Uganda. BMC Int Health Hum Rights 11(1):13. doi:10.1186/1472-698X/11/S1/S13

United Nations Secretary-General (2010) Global strategy for women's and children's health. http://www.who.int/pmnch/activities/ advocacy/fulldocument_globalstrategy/en/. Accessed 6 Mar 2015

Van Eerd D, Cole D, Keown K, Irvin E, Kramer D, Brenneman Gibson J, Kohn M, Mahood Q, Slack T, Amick BC, Phipps D, Garcia J, Morassaei S (2011) Report on knowledge transfer and exchange practices: a systematic review of the quality and types of instruments used to assess KTE implementation and impact. http://www.iwh.on.ca/sys-reviews/kte-evaluation-tools. Accessed 6 Mar 2015

Walter I, Nutley SM, Davies HTO (2005) What works to promote evidence-based practice? A cross-sector review. Evid Policy 1(3):335-364. doi:10.1332/1744264054851612

Wanyama JN, Castelnuovo B, Robertson G, Newell K, Sempa JB, Kambugu A, Manabe YC, Colebunders R (2012) A randomized controlled trial to evaluate the effectiveness of a board game on patients' knowledge uptake of HIV and sexually transmitted diseases at the Infectious Diseases Institute, Kampala, Uganda. J Acquir Immune Defic Syndr 59(3):253-258. doi:10.1097/QAI. 0b013e31824373d5

Weiss CH (1998) Have we learned anything new about the use of evaluation? Am J Eval 19(1):21-33. doi:10.1177/ 109821409801900103

WHO (2013a) World health report 2013: research for universal health coverage. http://www.who.int/whr/2013/report/en/. Accessed 6 Mar 2015

WHO (2013b) World health statistics 2013. http://www.who.int/gho/ publications/world_health_statistics/2013/en/. Accessed 6 Mar 2015

Willms DG, Arratia MI, Makondesa P (2011) Can interfaith research partnerships develop new paradigms for condom use and HIV prevention? The implementation of conceptual events in Malawi results in a 'spiritualised condom'. Sex Transm Infect 87(7):611-615. doi:10.1136/sextrans-2011-050045

World Bank (2013) Data: low-income countries. http://data. worldbank.org/income-level/LIC. Accessed 6 Mar 2015 